\title{
Application to a compacted soil of a Cam Clay model extended to unsaturated conditions
}

\author{
F. Casini \\ Università Roma "La Sapienza", Roma, Italy \\ R. Vassallo \\ Università della Basilicata, Potenza, Italy \\ C. Mancuso \\ Università “Federico II”, Napoli, Italy
}

\author{
A. Desideri \\ Università Roma "La Sapienza”, Roma, Italy
}

\begin{abstract}
This paper presents an interpretation of experimental results obtained at the Department of Geotechnical Engineering of the Università di Napoli Federico II. The results are part of an extensive program carried out to investigate the effects of partial saturation on the volumetric behaviour and on the initial shear stiffness of a compacted silt. Tests were performed using two suction-controlled devices, a triaxial cell and a Resonant Column Torsional Shear (RCTS) cell. The compatibility of experimental data with a Bishop Stress Model (BSM) is discussed in the paper. The BSM permits highlighting of the two main effects of suction on soil behaviour: the increase of the average stress acting on the soil skeleton and the hardening - cementing of the soil packing. Hydraulic hysteresis is included in the definition of the water retention curve so that its effects, such as the irreversible component of volume change recorded during drying paths, are automatically incorporated in the predictions of the model.
\end{abstract}

\section{INTRODUCTION}

An extensive experimental program was carried out at the Department of Geotechnical Engineering of the Università di Napoli Federico II to investigate the effects of partial saturation on the volumetric behaviour and on the initial shear stiffness, $G_{0}$, of a compacted clayey silt (Vassallo et al., 2007a). A first interpretation of the results was provided by Vassallo et al. (2007b), using an approach in terms of net stresses and suction in the framework of the Barcelona Basic Model.

In this paper some of the experimental data are re-interpreted using a Modified Cam Clay Model extended to unsaturated conditions (Jommi, 2000; Tamagnini, 2004). A similar approach has already been used by Casini et al. (2007) in order to understand if the model could predict the general features of the experimental results on the clayey silt. The model predicts correctly the influence of $S_{r}$ on compressibility. However, for the sake of simplicity, the hydraulic hysteresis of the water retention curve was neglected.
This work takes a step forward by accounting for hysteresis and its effects on soil behaviour. The focus is on tests which included a compression stage and, then, wetting-drying cycles.

\subsection{Material properties, experimental program}

The tested soil is the Po silt: a clayey-slightly sandy silt representative of the materials used for the construction of embankments on the Po river (Italy).

On average, the material has a liquid limit $\left(w_{L}\right)$ of $50.4 \%$, a plastic limit $\left(w_{P}\right)$ of $32.5 \%$ and therefore a plasticity index $\left(I_{P}\right)$ of $17.9 \%$. According to the Casagrande chart, it is classified as inorganic silt of medium/high compressibility.

The material was compacted at the optimum water content by using the Standard Proctor procedure (ASTM, 2005). Table 1 summarises the average properties of the silt after compaction.

Fifteen suction controlled tests were performed using a triaxial cell (Vassallo et al., 2007a). Three of them consisted of isotropic compression with 
Table 1. Average properties of the tested material after compaction.

\begin{tabular}{llll}
\hline $\mathrm{w}(\%)$ & $\gamma_{d}\left(\mathrm{kN} / \mathrm{m}^{3}\right)$ & $v$ & $S_{r}(\%)$ \\
\hline $23.1 \pm 0.3$ & $15.59 \pm 0.08$ & $1.731 \pm 0.009$ & $86.9 \pm 1.9$ \\
\hline
\end{tabular}

Table 2. Stress paths of tests mp05RC and mp07RC.

\begin{tabular}{|c|c|c|c|}
\hline \multicolumn{2}{|c|}{ mp05RC } & \multicolumn{2}{|c|}{ mp07RC } \\
\hline$p-u_{a}$ & $u_{a}-u_{w}(\mathrm{kPa})$ & $p-u_{a}$ & $u_{a}-u_{w}(\mathrm{kPa})$ \\
\hline 10 & 200 & 10 & 400 \\
\hline 200 & 200 & 200 & 400 \\
\hline 200 & 400 & 200 & 100 \\
\hline 200 & 100 & 200 & 400 \\
\hline 200 & 400 & 200 & 200 \\
\hline 200 & 100 & 550 & 200 \\
\hline 200 & 200 & - & - \\
\hline
\end{tabular}

unloading and reloading stages. In the other twelve tests, the samples were isotropically consolidated at constant suction and then sheared. Besides the fully saturated condition, suctions of 50,100, 200 and $400 \mathrm{kPa}$ were investigated.

Twelve suction controlled tests were carried out using a Resonant Column Torsional Shear (RCTS) cell (Vassallo et al., 2007a). During seven of them, after a preliminary equalization stage, an isotropic consolidation stage was carried out (in three cases including both loading and unloading) measuring almost continuously the initial stiffness $G_{0}$. The remaining five tests included stages of compression and of drying and wetting at constant mean net stress $\left(p-u_{a}\right)$, again with a continuous measure of the initial stiffness $G_{0}$. Overall, three levels of suction $(100,200,400 \mathrm{kPa})$ and mean net stresses ranging from 25 to $700 \mathrm{kPa}$ were investigated.

This paper focuses on two out of the five tests which included stages of drying and wetting. Table 2 summarises the stress paths followed in these tests, in terms of $\left(p-u_{a}\right)$ and matric suction $\left(u_{a}-u_{w}\right)$.

The soil parameters used to model the volumetric behaviour observed during these two tests are obtained from the complete set of isotropic stage results (both equalization and compression).

\section{ELASTO-PLASTIC MODEL}

\subsection{Bishop stress model}

The classic Bishop equation for effective stress is adopted:

$\sigma_{i j}^{\prime}=\sigma_{i j}-u_{a}+\chi\left(S_{r}\right)\left(u_{a}-u_{w}\right) \delta_{i j}$ where $\sigma_{i j}$ are total stresses, $u_{a}$ is the air pressure, $u_{w}$ is the water pressure, $\delta_{i j}$ is the Kronecker delta, $\chi\left(S_{r}\right)$ is a weighing parameter which can account for the effects of surface tension. In this work $\chi\left(S_{r}\right)$ was assumed equal to $S_{r}$. It has been argued that expression (1), often called Bishop's stress with $\chi\left(S_{r}\right)=S_{r}$, represents the average stress acting on the solid phase if one neglects the work of the air-water interface (Hassanizadeh \& Gray, 1980; Lewis \& Schrefler, 1987; Hutter et al., 1999).

Starting from the modified Cam Clay model for saturated conditions (Roscoe \& Burland, 1968) and using the conceptual framework proposed by Jommi (2000) and Tamagnini (2004), the model is formulated as follows.

As in the original modified Cam-clay model, elastic behaviour is defined by:

$\dot{\varepsilon}_{v}^{e}=\frac{1}{K} \dot{p}^{\prime} \quad \dot{\varepsilon}_{d}^{e}=\frac{1}{3 G} \dot{q}$

where $p^{\prime}$ is the mean effective stress, $q$ is the deviator stress, $\dot{\varepsilon}_{v}^{e}$ and $\dot{\varepsilon}_{d}^{e}$ are the increments of elastic volumetric strain and elastic deviatoric strain, respectively, $K$ is the bulk modulus and $G$ is the shear modulus.

The yield locus has the usual form:

$f=q^{2}+M^{2} p^{\prime} \cdot\left(p^{\prime}-p_{c}^{\prime}\right)$

where $M$ is the slope of the critical state line in the $p^{\prime}: q$ plane, and $p_{c}^{\prime}$ is the scalar internal variable (overconsolidation pressure) describing isotropic hardening. The evolution of $p_{c}^{\prime}$ is defined in terms of a double hardening mechanism:

$\dot{p}_{c}^{\prime}=\dot{p}_{c \text { sat }}^{\prime}+\dot{p}_{c \text { unsat }}^{\prime}$

where

$\dot{p}_{c s a t}^{\prime}=\frac{v p_{c}^{\prime}}{\lambda-\kappa} \dot{\varepsilon}_{p}^{v}$

describes the evolution of the yield function produced by plastic volumetric strains $\dot{\varepsilon}_{v}^{p}$ as predicted in the original model for saturated soils. Parameter $\lambda$ is the slope of the normal compression line, $\kappa$ is the slope of unloading-reloading lines, and $v$ is the specific volume. On the other hand, the expression:

$\dot{p}_{c \text { unsat }}^{\prime}=-b p_{c}^{\prime} \dot{S}_{r}$

describes the evolution of the yield surface produced by changes in the degree of saturation, which may occur even if the current stress lies in the elastic domain. Parameter $b$ is a constant soil property. 
The integration of Equation (4) yields to:

$p_{c}^{\prime}=p_{c s a t}^{\prime} \cdot \exp \left[b\left(1-S_{r}\right)\right]$

Thus, $b$ controls the rate of change in $p_{c}^{\prime}$ caused by variations in $S_{r}$.

Hardening has an irreversible component dependent on the development of plastic volumetric strains, related to the evolution of $p_{c \text { sat }}^{\prime}$, and a reversible component related to changes in $S_{r}$.

The model requires a hydraulic constitutive relationship describing the water storage mechanism, as shown in Figure 1. The retention curve $\theta_{w}=\theta_{w}(s)$ obtained upon an imbibition process differs from that obtained upon drying (hysteresis). Equilibrium at a given suction may be obtained with different $\theta_{w}$. The two main curves are linked by scanning curves that can be linear or not.

The issue of the hydraulic component of constitutive models was first addressed by Wheeler (1996) and by Dangla et al. (1997). Probably, the first full attempt to couple hydraulic behaviour with a mechanical model for unsaturated soils was proposed by Vaunat et al. (2000). More recently, Wheeler et al. (2003) presented an elastoplastic constitutive model that also fully couples hydraulic hysteresis with mechanical behaviour of unsaturated soils. A comprehensive review of constitutive models for unsaturated soils, including those based on Bishop's stress, was presented by Gens et al. (2006).

In this study the equation proposed by Van Genuchten (1980):

$\theta_{w}=\theta_{w s a t}\left[\frac{1}{1+(\alpha s)^{n}}\right]^{m}$

is used, where $\theta_{w}$ is the volumetric water content, $\theta_{\text {wat }}$ is the volumetric water content under saturated conditions and $s$ is matric suction.

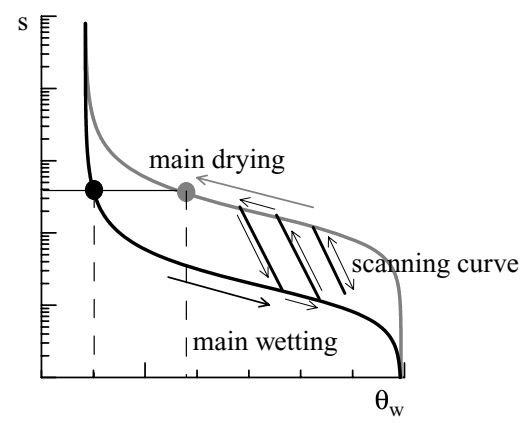

Figure 1. Constitutive relationships describing water storage mechanism.
The main drying and wetting curves are obtained assuming different values for the constitutive parameters $\alpha, n$ and $m$ (Romero \& Vaunat, 2000). Scanning curves are assumed linear in the $\theta_{w}: s$ plane:

$\dot{\theta}_{w}=-k_{s} \dot{S}$

in which the constitutive parameter $k_{s}$ is the slope of the scanning curves.

Since different values of $\theta_{w}$ can correspond to the same value of $s$, as shown in Figure 1, the hardening parameter $p_{c}^{\prime}$ in Equation (7) results smaller along the main drying curve than along the main wetting curve for the same values of suction and porosity.

The physical meaning of the assumptions above rests on the fact that lower degree of saturation implies a higher number of contact zones between the pore fluids (menisci) so that the bonding effect exerted by the menisci is higher along a wetting path than along a drying path (Tamagnini, 2004).

\subsection{Modelling of experimental results}

Figure 2 reports, in the $\theta_{w}: s$ plane, the 26 experimental points relative to the end of the equalization stages for all triaxial and resonant column tests together with the adopted water retention relationship. The average suction of the tested soil after compaction is about $140 \mathrm{kPa}$ (Vassallo et al., 2007a).

Therefore, equalization at suction 200 and $400 \mathrm{kPa}$ is a drying process while equalization at lower suction is a wetting process. Table 3 summarises the parameters chosen for the water retention curve.

All the available experimental data from compression stages were analysed to obtain the parameters of Equations (5) and (6), reported in Table 4.

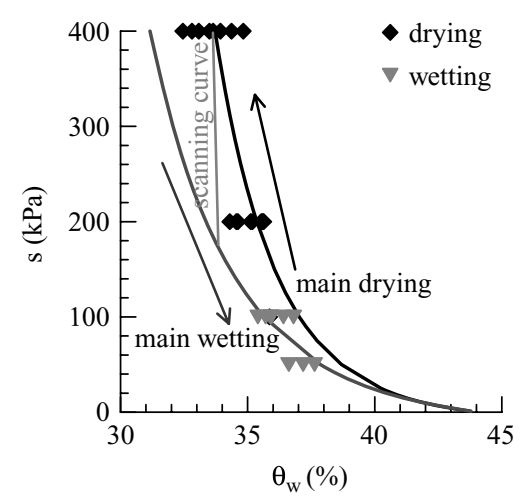

Figure 2. Experimental results of equalization stages versus the adopted water retention relationship. 
The performance of the model was verified for tests mp07RC and mp05RC, whose results are described in detail by Vassallo et al. (2007a).

Figure 3 a reports a comparison between model predictions and experimental results for test mp07RC. As reported in Table 2, this test consisted of a compression at constant suction $s=400 \mathrm{kPa}$, up to $p^{\prime} \cong 510 \mathrm{kPa}$ (path 0-1), followed by several wetting-drying stages to $s=100-400-200 \mathrm{kPa}$ (path 1-2-3-4) and finally by compression to $p^{\prime} \cong 710 \mathrm{kPa}$ (path 4-5). Experimental data for drying and wetting stages show only two data points at the beginning and at the end of each stage. Since suction was applied immediately at the boundary of the specimen, then waiting for the achievement of equilibrium, only the initial and final specific volumes can be attributed to the imposed net stress and suction. Differently, a complete $v: p^{\prime}$ curve was obtained for each stage by modelling.

During the first wetting stage at $s=100 \mathrm{kPa}$ (path 1-2) the material swells. During the following drying at $s=400 \mathrm{kPa}$ (path 2-3) there is a small accumulation of irreversible deformations due to the increase in suction, as shown by the specific volume at point

Table 3. Parameters describing soil water retention curve.

\begin{tabular}{llllll}
\hline & $\alpha\left(\mathrm{kPa}^{-1}\right)$ & $n$ & $m$ & $\theta_{\mathrm{w} \mathrm{sat}}(\%)$ & $k_{s}\left(\mathrm{kPa}^{-1}\right)$ \\
\hline Drying & 0.11 & 1.07 & 0.07 & 44 & 0.00256 \\
Wetting & 0.07 & 1.10 & 0.09 & 44 & 0.00256 \\
\hline
\end{tabular}

Table 4. Parameters describing soil compressibility and the evolution of the yield surface produced by changes in $S_{r}$.

\begin{tabular}{llll}
\hline$\lambda$ & $\kappa$ & $b$ & $N\left(S_{r}=1\right)$ \\
\hline 0.06 & 0.018 & 7 & 2.015 \\
\hline
\end{tabular}

3 which is smaller than that at point 1 . During the subsequent wetting at $s=200 \mathrm{kPa}$ (path 3-4) the material swells. Then, in the final stage of compression, the material seems to reach a normally consolidated state at $p^{\prime} \cong 490 \mathrm{kPa}$.

Model predictions are also reported in Figures $3 \mathrm{~b}$ and $3 c$ in $\theta_{w}: s$ and $p^{\prime}:\left(1-S_{r}\right)$ planes. An overconsolidated state is predicted at point 0 (beginning of compression). Points 0 and 1 lie on the main drying curve (Fig. 3b) as the imposed suction (400 $\mathrm{kPa}$ ) is greater than the after compaction suction. Compression stage $0-1$ does not affect the predicted value of $\theta_{w}$ (Fig. 3b). On the other hand, there is a change in $S_{r}$, and thus in variables $\left(1-S_{r}\right)$ and $p^{\prime}$, due to the change in porosity (Fig. $3 \mathrm{c}$ ). For this stage, the prediction in the $p^{\prime}: v$ plane is satisfying.

The model also predicts well soil behaviour for the wetting stage $1-2$ from $s=400 \mathrm{kPa}$ to $s=100 \mathrm{kPa}$, that lies completely in the elastic domain, and for the drying stage $2-3$ from $s=100 \mathrm{kPa}$ to $s=400 \mathrm{kPa}$, that represents an elasto-plastic path. In the first case the state path follows first a scanning curve and then reaches the main wetting curve; in the second case, the model predicts that the state path returns to the same value of $\theta_{w}$ of points $0-1$. Furthermore, the model predicts some (slight) hardening in the $p^{\prime}:\left(1-S_{r}\right)$ plane due to the different changes which both $p^{\prime}$ and $p^{\prime}{ }_{c}$ experience along paths 1-2 and 2-3 (Fig. 3c).

The subsequent wetting $3-4$ to $\mathrm{s}=200 \mathrm{kPa}$ only induces elastic strains, in good agreement with experimental data. The final compression stage is also well predicted by the model.

Figure 4a compares experimental results to model predictions for test mp05RC. This test included a compression at constant suction $s=200 \mathrm{kPa}$, up to $p-u_{a}=200 \mathrm{kPa}$ (path 0-1), then several dryingwetting stages $s=400-100-400-100-200 \mathrm{kPa}$ (path 1-2-3-4-5-6) (see Table 2). (a)

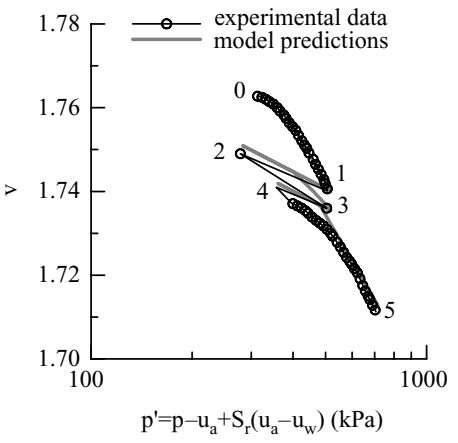

(b)

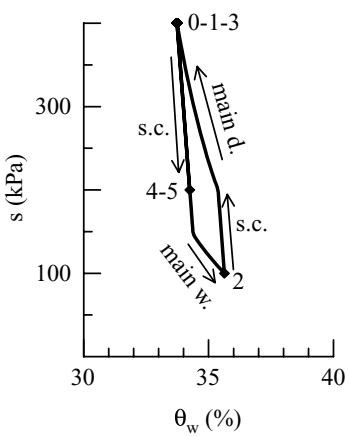

(c)

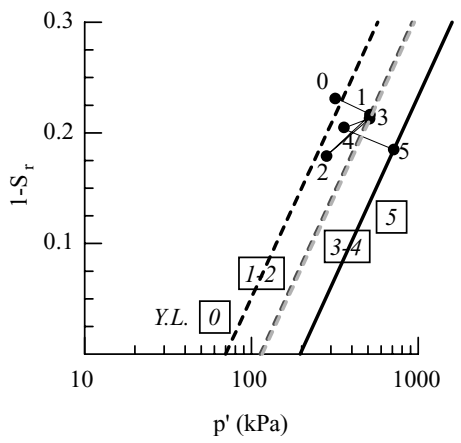

Figure 3. Test mp07RC. Experimental data versus predictions in $p^{\prime}: v$ plane (a); predictions in $\theta_{w}: s$ plane (b) and $p^{\prime}:\left(1-S_{r}\right)$ plane (c). 
(a)

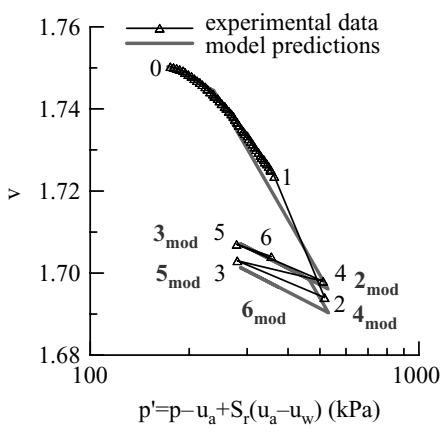

(b)

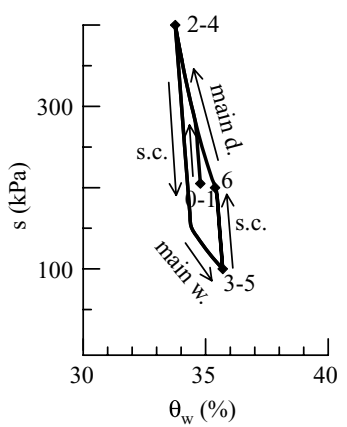

(c)

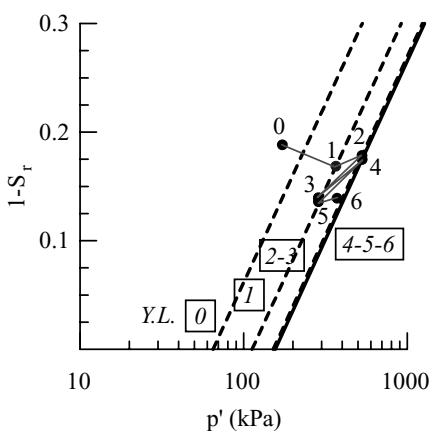

Figure 4. Test mp05RC. Experimental data versus predictions in $p^{\prime}: v$ plane (a); predictions in $\theta_{w}: s$ plane (b) and $p^{\prime}:\left(1-S_{r}\right)$ plane (c).

The first drying at $s=400 \mathrm{kPa}$ (path 1-2) induces irreversible deformations due to the increase in suction above its maximum past value (Vassallo et al. 2007ab). The irreversibility of previous volume changes is shown by the much smaller absolute value of the variation of $v$ observed during the first wetting at $\mathrm{s}=100 \mathrm{kPa}$ (path 2-3). As expected, this wetting path induces swelling. The subsequent drying and wetting stages cause volume changes comparable to those of wetting 2-3 and smaller than those of drying 1-2. The material always swells along wetting paths and shrinks along drying paths. Substantially, all the experimental points, from 2 on, are very close to a single line in the $p^{\prime}: v$ plane.

Figures $4 \mathrm{~b}$ and $4 \mathrm{c}$ show model predictions in the $\theta_{w}: s$ and $p^{\prime}:\left(1-S_{r}\right)$ planes. The model predicts an overconsolidated state at the beginning of compression. Similarly to test mp07RC, the results of the first compression stage are well predicted. The model also predicts an irreversible reduction of $v$, quite close to the measured one, during the subsequent drying 1-2 to $s=400 \mathrm{kPa}$. For the model, the path $2-3$ from $s=400 \mathrm{kPa}$ to $s=100 \mathrm{kPa}$ is elastic. The second drying 3-4 to $s=400 \mathrm{kPa}$ is elasto-plastic like the first one, although predicted shrinkage is much smaller than for path 1-2. Irreversible strains along cycle 2-3-4 are due to the different changes which $p^{\prime}$ and $p_{c}^{\prime}$ experience along path 2-3 and 3-4 (Fig. 4c), linked to the shape of the water retention relationship in the $\theta_{w}: s$ plane (Fig. 4b). The closed cycle in this plane does not correspond to a closed cycle in the $S_{r}: s$ plane, which is relevant for model predictions. The second wetting 4-5 and the final drying 5-6 are elastic. It is worth noting that the measured value of $v$ in point 2 is slightly smaller than that of point 4 , i.e., the material accumulates a small swelling during a drying-wetting cycle. This cannot be easily explained from a physical point of view and could be due to incomplete equalization during some stages of the test. More appropriately the model predicts a slight accumulation of shrinkage. However predictions are substantially in good agreement with measurements from point 2 to point 6 .

Points 0 and 1 in Figure $4 \mathrm{~b}$ lie on a scanning curve because the imposed suction, $s=200 \mathrm{kPa}$, is just slightly higher than the after compaction suction. Similarly to test mp07RC, which was analyzed above, compression 0-1 does not influence the value of $\theta_{w}$ while it changes porosity and, thus, variables $p^{\prime}$ and $\left(1-S_{r}\right)$, as shown in Figure 4c. During the first drying 1-2, the main drying curve is reached and the yield locus is significantly shifted rightwards. This confirms that path 1-2 is elasto-plastic. During the wetting 2-3 a scanning curve is followed until the main wetting curve is reached; an elastic path is predicted in the plane $p^{\prime}:\left(1-S_{r}\right)$. The same value of $\theta_{w}$ as at point 2 is reached after the second drying path 3-4. The model predicts a slight hardening, i.e., a slight further shift rightwards of the yield locus, linked to the different changes which both $p^{\prime}$ and $p_{c}^{\prime}$ experience along paths 2-3 and 3-4 (Fig. 4c). The yield locus remains unvaried during the final wetting-drying stages 4-5-6.

\subsection{Interpretation of stiffness measurements}

Vassallo et al. (2007a-b) used the framework of the Barcelona Basic Model to interpret the measurements of initial shear stiffness $G_{0}$ along both compression and wetting-drying paths. It was concluded that there is a significant influence of suction on stiffness, which generally increases as $\left(u_{a}-u_{w}\right)$ increases. Nevertheless, changes of suction may cause significant accumulation of irreversible changes of specific volume, accompanied by a further increase of $G_{0}$ relative to a general stress state $\left(p-u_{a}\right),\left(u_{a}-u_{w}\right)$. In other words, there can be a significant effect of the stress history, expressed in terms of $\left(p-u_{a}\right)$ and $\left(u_{a}-u_{w}\right)$, on the initial stiffness. 

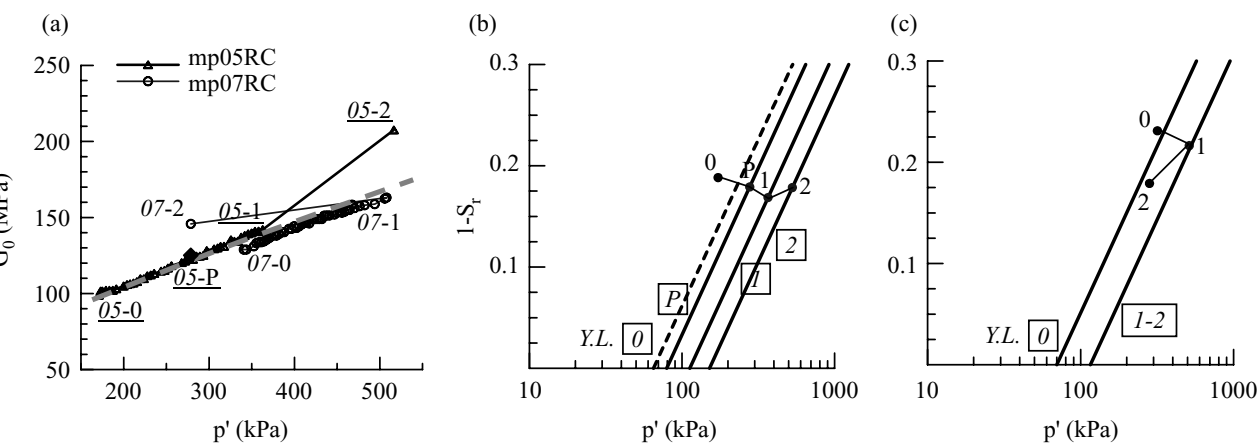

Figure 5. Measured initial stiffness $G_{0}$ versus $p^{\prime}$ for tests mp05RC and mp07RC (a); predictions in the $p^{\prime}:\left(1-S_{r}\right)$ plane for tests mp05RC (b) and mp07RC (c).

As highlighted by Casini et al. (2007), an alternative approach is using Equation (1) and referring $G_{0}$ measured values to corresponding $p^{\prime}$ values. This way, the effects of partial saturation on the initial shear stiffness result similar to those ascribable to the structure of a natural soil compared to the same soil reconstituted (Rampello et al. 1994). In fact, as far as data collected during isotropic compression are concerned, moving from complete saturation to partial saturation induces a translation of experimental $G_{0}: p^{\prime}$ curves.

Figure 5a reports for tests mp05RC and mp07RC stiffness versus $p^{\prime}$, measured during the first compression stage and the subsequent first wetting or drying stage. Compression stage data belong to a narrow range centred on the dashed line plotted in the same figure. This proves that the stiffness of the unsaturated soil can be fundamentally interpreted by a single curve in the $p^{\prime}: G_{0}$ plane. On the other hand, the stiffness measured after a drying or a wetting stage results significantly higher than the values on the dashed curve. Comparison can be made between points 05-2 and $07-1$, characterized by the same $\left(p-u_{a}\right)$ and $\left(u_{a}-u_{w}\right)$, and $05-\mathrm{P}$ and $07-2$, characterized by the same $p^{\prime}$. This suggests that there is also an effect of stress history in terms of Bishop's stress.

Figures $5 \mathrm{~b}$ and $5 \mathrm{c}$ report model predictions in the plane $p^{\prime}:\left(1-S_{r}\right)$ for the same tests. Point 2 of test mp05RC and point 1 of test mp07RC belong to different yield loci and have different $\left(1-S_{r}\right)$ and $p^{\prime}$. The yield locus is more expanded for test mp05RC. As a consequence of different history, point $\mathrm{P}$ of test $\mathrm{mp} 05 \mathrm{RC}$ is on the current yield locus while point 2 of test mp07RC is inside the yield locus. All this could justify the differences in measured stiffness.

\section{CONCLUDING REMARKS}

This paper verifies the possibility of interpreting some data from the comprehensive experimental study by
Vassallo et al. (2007a) within the framework of a Bishop Stress Model (BSM).

Casini et al. (2007) had already confirmed that the BSM can interpret the progressive shift of normal consolidation lines as the degree of saturation decreases and, more in general, the influence that $S_{r}$ has on compressibility.

Herein, a step forward was taken in modelling, by accounting for the hysteresis of the water retention curve and for its effects on soil behaviour. This determines a hysteresis in the internal variable describing isotropic hardening (Tamagnini, 2004) and can justify the occurrence of irreversible deformations such as those induced by drying-wetting cycles.

The predictions of the chosen model are in good qualitative and quantitative agreement with the experimental data in terms of specific volume changes plotted versus Bishop mean effective stress $p^{\prime}$. The representation of test paths and of yield loci in the plane $p^{\prime}:\left(1-S_{r}\right)$ also seems quite useful to interpret the effects of stress state and stress history on the initial shear stiffness $G_{0}$.

\section{REFERENCES}

ASTM 2005. D0698-00 AE01 Test method for laboratory compaction characteristics of soil using standard effort $\left(12,400 \mathrm{ft} \cdot \mathrm{lbf} / \mathrm{ft}^{3}\left(600 \mathrm{kN} \cdot \mathrm{m} / \mathrm{m}^{3}\right)\right)$, ASTM Book of Standards, vol. 04.08, Philadelphia, USA.

Casini F., Vassallo R., Mancuso C. \& Desideri A. 2007. Interpretation of the behaviour of compacted soils using Cam-Clay extended to unsaturated conditions. Proceedings of the Second International Conference Mechanics of Unsaturated Soils, Weimar (Germany), 29-36.

Dangla O.L., Malinsky L. \& Coussy O. 1997. Plasticity and imbibition-drainage curves of unsaturated soils: a unified approach. 6th International Conference on numerical models in geomechanics, Montreal, 141-146.

Gens A., Sanchez M. \& Sheng D. 2006. On constitutive modelling of unsaturated soils. Acta Geotechnica, 1, 137-147. 
Hassanizadeh S.M. \& Gray W.G. 1980. General conservation equations for multiphase systems: 3 . Constitutive theory for porous media flow. Advanced Water Resource, $3,25-40$.

Hutter K., Laloui L. \& Vulliet L. 1999. Thermodynamically based mixture models for saturated and unsaturated soils. Mechanics of Cohesive-frictional Materials, 4, 295-338.

Jommi C. 2000. Remarks on the constitutive modelling of unsaturated soils. Proceedings of the International Workshop Experimental Evidence and Theoretical Approaches in Unsaturated Soils, Trento (Italy), 139-153.

Lewis R.W. \& Schrefler B.A. 1987. The finite element method in the deformation and consolidation of porous media. Wiley, Chichester.

Rampello S., Silvestri F. \& Viggiani G. 1994. The dependence of small strain stiffness on stress state and history for fined grained soils: the example of Vallericca clay. Proceedings of the First International Symposium on Prefailure Deformation of Geomaterials, Sapporo (Japan), 273-278.

Romero E. \& Vaunat J. 2000. Retention curves of deformable clay. Proceedings of the International Workshop Experimental evidence and theoretical approaches in unsaturated soils, Trento (Italy), 91-106.

Roscoe K.H. \& Burland J.B. 1968. On the Generalized StressStrain Behavior of Wet Clay. Engineering Plasticity, Cambridge University Press, 535-609.
Tamagnini R. 2004. An extended Cam-clay model for unsaturated soils with hydraulic hysteresis. Géotechnique, 54, 223-228.

Van Genuchten M.T. 1980. A closed-form equation for predicting the hydraulic conductivity of unsaturated soils. Soil Science Society of America Journal, 44, 892-898.

Vassallo R., Mancuso C. \& Vinale F. 2007a. Effects of net stress and suction history on the small strain stiffness of a compacted clayey silt. Canadian Geotechnical Journal, 44, 447-462.

Vassallo R., Mancuso C. \& Vinale F. 2007b. Modelling the influence of stress-strain history on the initial shear stiffness of an unsaturated compacted silt. Canadian Geotechnical Journal, 44, 463-472.

Vaunat J., Romero E. \& Jommi C. 2000. An elastoplastic hydro-mechanical model for unsaturated soils Proceedings of the International Workshop Experimental evidence and theoretical approaches in unsaturated soils, Trento (Italy), 121-138.

Wheeler S.J. 1996. Inclusion of specific water volume within an elastoplastic model for unsaturated soil. Canadian Geotechnical Journal, 33, 42-57.

Wheeler S.J., Sharma R.S. \& Buisson M.S.R. 2003. Coupling of hydraulic hysteresis and stress strain behaviour in unsaturated soils. Géotechnique, 53, 41-54. 
